\title{
Human Activities in Historical Period and Ecological Changes in Shiyang River Basin
}

\author{
Xiaoyong Huang \\ College of History and Culture \\ Northwest Normal University \\ Lanzhou, China 730070
}

\begin{abstract}
Shiyang River Basin has attracted much attention due to its important ecological and economic status and the deteriorating ecological environment. This paper studies the change of the location of the site, the migration of the residential site, the change of the production tools and the living utensils and the difference of the funerary objects through the analysis of the data, so as to analyze the profound influence of the environmental change on the economic form and the human society, find the relationship between human activities in this region and the environmental change, and provide reference for environmental protection of Shiyang River Basin today.
\end{abstract}

Keywords-Shiyang River; ecological economy; human-earth relationship

\section{INTRODUCTION}

Shiyang River is one of the four major inland rivers in Hexi area of Gansu Province. It originates from Lenglongling of Qilian Mountains, flows through Qilian Mountains, Hexi Corridor Plain, Zoulang Beishan and Alxa Plateau. The basin covers an area of $4.1 \times 104 \mathrm{~km} 2$ and the water resources quantity is about $16.9 \times 108 \mathrm{~m} 3$. Qilian Mountains formed due to the collision between Eurasian continent and the Indian subcontinent since Cenozoic. The tall mountains not only have a large number of solid reservoirs - glaciers, but also retain a large amount of water vapor from high altitude and rainfall from local circulation. Wuwei Basin and Minqin Basin as well as a large number of rivers originating from the eastern Qilian Mountains flow into Shiyang River and format the current oasis ecosystem in Shiyang River Basin. Based on the analysis of the historical relics of Shiyang River Basin, from the change of the location of the site, the migration of the residential site, the change of the production tools and the living utensils and the difference of the funerary objects, this paper analyzes the profound influence of the environmental change on the economic form and the human society, and discusses the relationship between man and nature in Shiyang River Basin and its evolution. It has a clear practical significance for the economic development and environmental protection of Shiyang River Basin "Fig. 1".

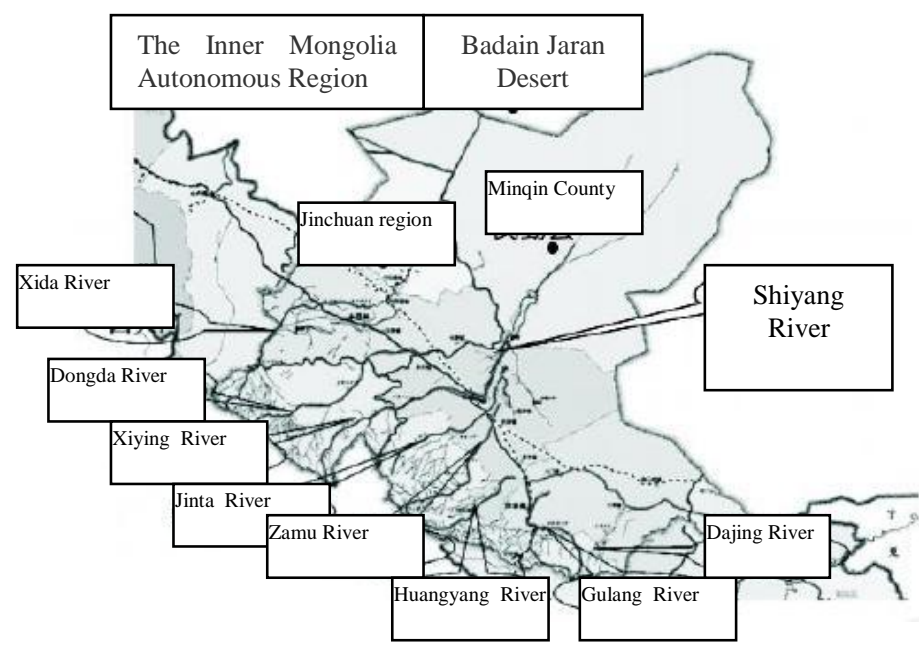

Fig. 1. A map of Shiyang River Basin

II. ECOLOGICAL ECONOMY OF SHIYANG RIVER BASIN BEFORE THE WESTERN HAN DYNASTY (HE NEOLITHIC AGE $121 \mathrm{BC})$

Before the large-scale development of Shiyang River Basin in the Western Han Dynasty, snow water flowing from the eastern part of Qilian Mountains flows through several rivers into the ancient Shiyang River, and then into the ancient Terminal Lake in Minqin Basin (called as Zhuyeze in ancient times), forming the landscape of "Shiyang River, Jinchuan downstream alluvial plain".

The remains of Shiyang River Basin in the Neolithic Age to the Bronze Age were mainly Majiayao Culture (3300 BC 2050 BC), Qijia Culture (2200 BC - 600 BC) and Shajing Culture (600 BC - $500 \mathrm{BC})$. The large pottery urn filled with millet unearthed in Yuanyangchi site M134 (M means tomb) of Machang type of Majiayao Culture in Wuwei City, and small pottery cup similar to wine glass unearthed from M69, M153 reflect that there had been considerable surplus of grain at that time, and could be used to provide wine. Huangniangniang Site in Liangzhou District, Wuwei City is the typical representative of Qijia Culture in Shiyang River Basin. A large number of agricultural production tools such as stone axes, stone knives, stone adzes and stone sickles were unearthed in this site. It can be seen that the agriculture had been greatly developed at that time. 
Four houses, were found in Shajing Culture Sanjiaocheng Site, all with stove pits. 20 tombs were excavated in Hamadun Site, and a large number of copper knives, copper cones, iron knives, arrowheads, arrows, bow leather and wool textiles were unearthed. During Shajing Culture Period, animal husbandry was the main economic form in Shiyang River Basin, supplemented by agricultural economy and handicraft industry. It is inferred that Shajing Culture was the remnant of the ancient Rouzhi people, and believed that the original residence of Rouzhi was at the eastern end of Hexi Corridor. ${ }^{1}$

To sum up, human activities in the Neolithic and Bronze Ages were little influenced by the natural environment, and Shiyang River Basin almost completely followed the natural landscape and developed, rarely influenced by human beings.

\section{THE ECOLOGICAL ECONOMY OF SHIYANG RIVER BASIN IN THE HAN DYNASTIES (202 BC - 220 AD)}

In the early years of the Western Han Dynasty, the Huns occupied Shiyang River Basin, with animal husbandry as the main economic form, supplemented by agriculture.

\section{A. Cultural Relics}

During the Han Dynasties, in order to resist the harassing attack of the Huns and other nomads, the government built the Great Wall of the Han Dynasty and the city here. The site of Xiutu City built in the Huns era remains in the upper-middle reaches. There was Xuci County of Han Dynasty in Wangjingzhai, Donghe Township, Liangzhou District. In addition, there was also Tuanzhuangying Site in Jiudun Township, Shidun Temple Site, Zhangyibao Site in Zhangyi Town, and Gaogoubao Site in Changcheng Township. There were sites of ancient Heisongyi City and Gancheng City in Gulang County. In Xishawo area in the west of Minqin in the lower reaches of Shiyang River Basin, the site of Wenyi City, the ancient city, Liancheng and Sanjiaocheng distributed along the Shiyang River from north and south, and the remnants of the ancient city sites of Han Dynasty include: Chaiwan City Site, Nanyuebao City Site, Dong'anbao ancient city, Hongshabao City Site. The distribution of a large number of city sites indicates that the environment of Shiyang River Basin during this period was suitable for human survival and that a large number of human beings lived here. The city sites in the lower reaches of Shiyang River Basin during the Han Dynasties seemed to concentrate in the middle and upper reaches, indicating that the ecology of the lower reaches was not a seriously threatened by the desert as we now see.

\section{B. Economic Development}

The entry of large numbers of immigrants and the reclamation of cultivated land in the Han Dynasties brought Shiyang River Basin a great development in the Han Dynasty. An iron plow was respectively found in Chenjiahetai in Gulang County and Mojuzi Han Tomb in Wuwei. A total of 23 bales of various crops were unearthed in Mojuzi No. 6 Han Tomb, containing broom corn millet, buckwheat and hemp seed. In another Han tomb, archaeologists found the remains of jujube. 9 wooden horses, 18 wooden chickens, 9 wooden cattle, 6 wooden dogs and 10 wooden sheep were unearthed in Wuwei Mojuzi, ${ }^{2}$ fully reflecting the development of agriculture and animal husbandry at that time.

\section{Ecological Landscape}

The first great development of Hexi Corridor in the history took place during the Han Dynasties, so did Shiyang River Basin. Large-scale development led to ecological deterioration, and the area of the Terminal Lake in the lower reaches shrank. During the Han Dynasties, the area of the lake area decreased by $44 \%$ compared with the prehistory period ${ }^{3}$. The shortage of water resources made people rely more heavily on groundwater, and pottery wells were generally buried with the dead in the Tombs of the Eastern Han Dynasty in Shiyang River Basin, indicating people's dependence on groundwater. During this period, human factors played an important role in the eco-economic development and environmental damage in Shiyang River Basin. At this point, the original ecological landscape of Shiyang River Basin began to change.

\section{THE ECOLOGICAL ECONOMY OF SHIYANG RIVER BASIN IN THE PERIOD OF WEI JIN AND SOUTHERN AND NORTHERN DYNASTIES (AD 222 - 589)}

The Period of Wei Jin and Southern and Northern Dynasties was a relatively chaotic period in our history, and Shiyang River Basin was still influenced by the national turmoil although it was in the remote Hexi region. In this period, the cities in Shiyang River Basin, apart from those abandoned ones, followed the old cities of Han Dynasty, which is not specified here.

\section{A. Economic Development}

The agricultural development of Shiyang River Basin experienced an unsmooth from Wei and Jin Dynasties and to the Northern Dynasties. Murals reflecting the farming situation such as plowing, farming and harrowing were found in the mural tombs of Wei and Jin in Jiayuguan. Tools such as plough, harrow and fork were found in Hexi area. The murals shew that the tillage method had transformed from a yoke of two cattle for tilling in Han Dynasty to the more advanced one cattle pulling; and the shoulder yoke previously used was replaced by bent yoke. At the same time, the silkworm industry also gradually developed in this period. There were 15 kinds and 8 types of silk fabrics with fine texture were unearthed in Wuwei Mojuzi Han Tomb, which may well be the local product of Shiyang River Basin. The prosperity of the silk industry at that time can be seen from these.

\section{B. Ecological Environment}

In the Period of Wei Jin and Northern Dynasties, the climate turned cold and dry, and the society was turbulent. In this period, Shiyang River Basin still continued the cold since the Han Dynasties, "it reached the coldest in 460AD, after which the temperature rose again in fluctuations, and entered the warm period in 560AD". 4 Under the cold climatic conditions, the agricultural production was affected, and the proportion of nomadic economic components increased. Although the development of agriculture slowed down, large 
amounts of water resources continued to be cut off in the upper and middle reaches, and less water flowed into the Terminal Lake in the lower reaches. To the sixth century, the Terminal Lake was divided into two separate lakes named the East Sea and the West Sea. The shortage of water resources made people dig a lot of wells, and pottery wells were generally buried with the dead in the Tombs of Wei and Jin Dynasties in Shiyang River Basin, indicating people' $s$ dependence on groundwater resources. In general, the ecology of Shiyang River Basin in the Period of Wei Jin and Northern Dynasties continued to be destroyed, but the speed was lower than that of the Han Dynasties. The destruction of the ecological environment continued and the ecological landscape was further deteriorating.

\section{LARGE-SCALE DEVELOPMENT OF THE OASIS IN THE MIDDLE REACHES IN SUI AND TANG DYNASTIES (AD 580 - 907)}

In Sui Dynasty, Wuwei County was set in Wuwei City today. Liangzhou was the political, economic, cultural center and important military post in the eastern area of Hexi. It can be seen from the setting of prefectures and counties in Tang Dynasty that the location was in the upper reaches of Shiyang River.

\section{A. Cultural Relics}

The city sites in the lowers reaches of Shiyang River were mostly built in the Han Dynasties and continued to be used in Tang Dynasty, such as Minqin Liancheng Site located in Quanshan Town, Han Wuwei County, Minqin Ancient City, Xuanwei Ancient City, and Duanzihao Chaiwan City Site. It can be seen from the distribution of the ancient city sites that the administrative city sites in Sui and Tang Dynasties were mainly distributed in the middle reaches of Shiyang River Basin, and no such sites were found in the lower reaches. The city sites in the lower reaches were mostly built in Han Dynasties and continued to be used in Tang Dynasty, generally used as a military garrison, and it could be seen that the lower reaches of Shiyang River were mainly for border defence in Sui and Tang Dynasties, not the focus of economic development.

Has been found in the Sui and Tang dynasties tombs are mainly Caizhu Lama Bay tombs, Song Jiayuan Tang tomb, Zhai family tomb and Yangjia Tombs and so on. From the distribution of the tomb can be seen, the tomb is mainly distributed in the upper reaches of Shiyang River area, along the Silk Road. This situation from the side reflects the Tang Dynasty Shiyang River Basin development focus, mainly concentrated in the middle reaches of the region.

\section{B. Economic Development}

In Sui Dynasty, in order to enrich the frontier defense forces, fortress fields were set in various places in Hexi, and the agricultural production developed. In Tang Dynasty, the farming methods of agriculture in Hexi area had made significant progress, and Shiyang River Basin was the thoroughfare of the Silk Road. It can be seen from the inspection of the sites of the Silk Road that it mainly passed
Changsong, Guzang and Fanhe. This had an important influence on the development of this area. The prosperity of the Silk Road promoted the integration of the nations in the northwest. In early years of Zhenguan Period, Xuanzang said that "Hexi metropolis border western states, and traveling merchants never stop" on his way westward to Guzang.

The increase in population increased water consumption in the middle reaches. People in the edge of the oasis had long been digging wells to obtain drinking water. A well site was found 800 meters north of Wudun Village, Changcheng Village, indicating that the wells were generally used to obtain water at that time.

\section{Ecological Landscape}

In Sui and Tang Dynasties, the climate became warm and wet. The climate entered the warm period again in about 560 $\mathrm{AD}$, and the warm period lasted to about 630 . From 640 to 800 , it was typical cold and wet climate. ${ }^{5}$ In general, it was mainly warm and wet in the early stage of Sui and Tang Dynasties, and turned a little dry since the end of Tang Dynasty, which had a great influence on the hydrological circulation and water resources of Shiyang River Basin, and the ecological environment was gradually deteriorated. Until about the 6th century, the complete lakes (Zhuyeze in broad sense) were divided into two lakes, namely West Sea and the East Sea, and the Minqin Xishawo Oasis with vast fields in the past had thus become a desert. As a result, the ecological economy of Shiyang River Basin became more fragile and the ecological landscape gradually changed to artificial oasis.

\section{ECOLOGICAL ECONOMY OF SHIYANG RIVER BASIN IN XIXIA PERIOD (AD 1038 - 1227)}

In AD 1038, Xixia captured Liangzhou from Tubo, putting an end to the situation of various regimes and frequent wars here since An Shi Rebellion.

\section{A. Cultural Relics}

In Xixia period, a large number of the ancient cities of the Han Dynasties were repaired the used. The upper reaches of Shiyang River: Tuanzhuangying Site, Shidun Temple Site. In addition, new cities such as Wanguantan Site were built. Lower reaches of Shiyang River: Chaiwan City Site, Nanyuebao Site, the ancient city of Donganbao. In addition, new cities such as the ancient city of Qingsongbao were built. It can be seen from the use of the city site that the number of old cities of Han Dynasty repaired and used by Xixia exceeded that of Sui and Tang Dynasties, and the distribution range was wider than the previous dynasties. Jiudun Township in the upper reaches belonged to the edge area of the oasis, which was once abandoned in Han Dynasties. The cities in this area were repaired and used in Xixia. In the lower reaches of Shiyang River, a large number of Han cities continued to be used, and new cities were built. The sites of the cities built are mainly in the south of Minqin County now, further south than that of the previous dynasties. This phenomenon reflects the use of Shiyang River Basin in Xixia was based on the previous dynasties, whose scope exceeded the previous dynasties, 
mainly extending to the edge of the oasis. But the development of the lower reaches was inferior to Han Dynasty.

\section{B. Economic Development}

Xixia regime vigorously advocated the reclamation of wasteland. The graphic evidence can be found in Anxi Yulin Grottoes. The pictures that shew agricultural and handicraft production such as plowing, pounding, making wine and forging iron were painted in No.3 Cave of Yulin Grottoes Cave. 7 Xixia cremation tombs were found in the western suburbs of Wuwei, and 35 wooden paintings were unearthed. The pictures show only chicken, dog and pig, but no cattle, sheep or camel, indicating that the economic life in the upper reaches of Shiyang River is dominated by agriculture.

Handicraft industry was developed in Xixia, with elaborate institutions and division of labour. The development of agriculture led to an increase in grain production and the development of wine. There were a lot of porcelain kilns in the ancient urban and rural areas of Liangzhou District, Wuwei City in Xixia Period, and the rapid development of porcelain industry let to great demand for raw materials and fuelwood. It needed to destroy the surface vegetation and change the landform for obtaining earth. The furnace temperature was high in kilns, and fuelwood needed a lot of wood, which could not be replaced by general hay, and the long-lasting wood chopping led to great damage to the ecological forest in the upper reaches.

\section{Ecological Landscape}

In Xixia period, the climate tended to cold, transiting from the warm period in the 9th and 10th centuries to the cold period in the 12th and 13th centuries, and this alternation lasted for more than 500 years. The precipitation continued to decrease during this period compared with the alternating temperature, making Shiyang River Basin experience a drought period for more than 500 years. Xixia's development of this area, in addition to restoring agricultural production, made the animal husbandry develop rapidly. From the view of development fields, the use of vegetation increased during this period. In Xixia period, the ecological environment of Shiyang River Basin was relatively good, mainly because the economic form of developing both agriculture and animal husbandry was adapted to the self-regulation and circulation of its ecological environment.

\section{The ECOLOGICAL ECONOMY IN MING AND QING DYNASTIES (AD 1368-1912)}

In Ming Dynasty, water conservancy projects were built and fields were vigorously reclaimed in places like Wuwei in Shiyang River Basin. Qing Dynasty continued to develop this region, which made the newly developed region break through the Great Wall, and the agricultural development entered the historical heyday.

\section{A. Cultural Relics}

The change of the location of the Great Wall was an important feature of Shiyang River Basin Site in Ming Dynasty. Wuwei section of Mingwei Great Wall was located in the area of Huangyang Town, Wujiajing Township, Qingyuan Town, Changcheng Township, Xiacheng Township, and Jiudun Township in the east of Wuwei. Han Great Wall was further east in the eastern part of Wuwei, including Yongfeng Township in Gulang County and most of Wujiajing Township in Liangzhou District. In contrast, Ming Great Wall clearly retreats westward.

Only a pond remains in Tanshanbao Site, which is round, 50 meters in diameter, 4 meters deep, and there is still water now. The pond was artificially dug to retain water for the local garrison and soldiers. There was relic of pond in the northwest corner of Shacheng City Site. It reflects the abundant precipitation and surface runoff in the alluvial sector in the upper reaches, and also shows that the runoff was more used in the upper reaches. This changed the temporal and spatial distribution of surface water, and would certainly have an influence on the downstream water.

It can be seen that the castles of Ming Dynasty are mainly constructed in the south of the Great Wall, concentrating in the middle and upper reaches of Shiyang River, which shows that the agricultural development and utilization in Ming Dynasty is concentrated in the middle and upper reaches. The ancient architectural sites of Qing Dynasty reflected the development of the lower reaches of Shiyang River in Qing Dynasty. The construction of the temple was closely related to the increase in the agricultural population in this area, which clearly broke through the original geographical development boundary in the south of the Great Wall in Ming Dynasty.

\section{B. Economic Development}

In addition to the development on the original basis in the upper reaches, large-scale reclamation and immigration emerged in the lower reaches of Shiyang River, where the reclamation area expanded to the east side of Xishawo, and the dam area in Minqin County today (from north Hongyashan Reservoir to Datan) became a new reclamation area. To Wanli Period in Ming Dynasty, the arable lands in Wuwei and the Minqin have reached $800 \times 104 \mathrm{hm} 2 .{ }^{6}$ The shortage of water resources had seriously affected the farmland irrigation in the lower reaches, and competition for irrigation occurred from time to time. Hongshaliang watermark monument remains in Shengyun Temple in Minqin, which was set up in the 41st year of Qianlong's reign (1777). The inscription on the monument was intaglioed in regular script, recording the story that the magistrate of Zhenfan County requesting to set up stone monument for the magistrate of Liangzhou, Gansu hearing the case of the fight for Qiushui among Mingtouba, Siquba and Hongshaliang in the 41st year of Qianlong's reign (1776) "Table I" and "Table II". 
TABLE I. TREND Chart OF PoPUlation AND Change OF ARABLE LAND
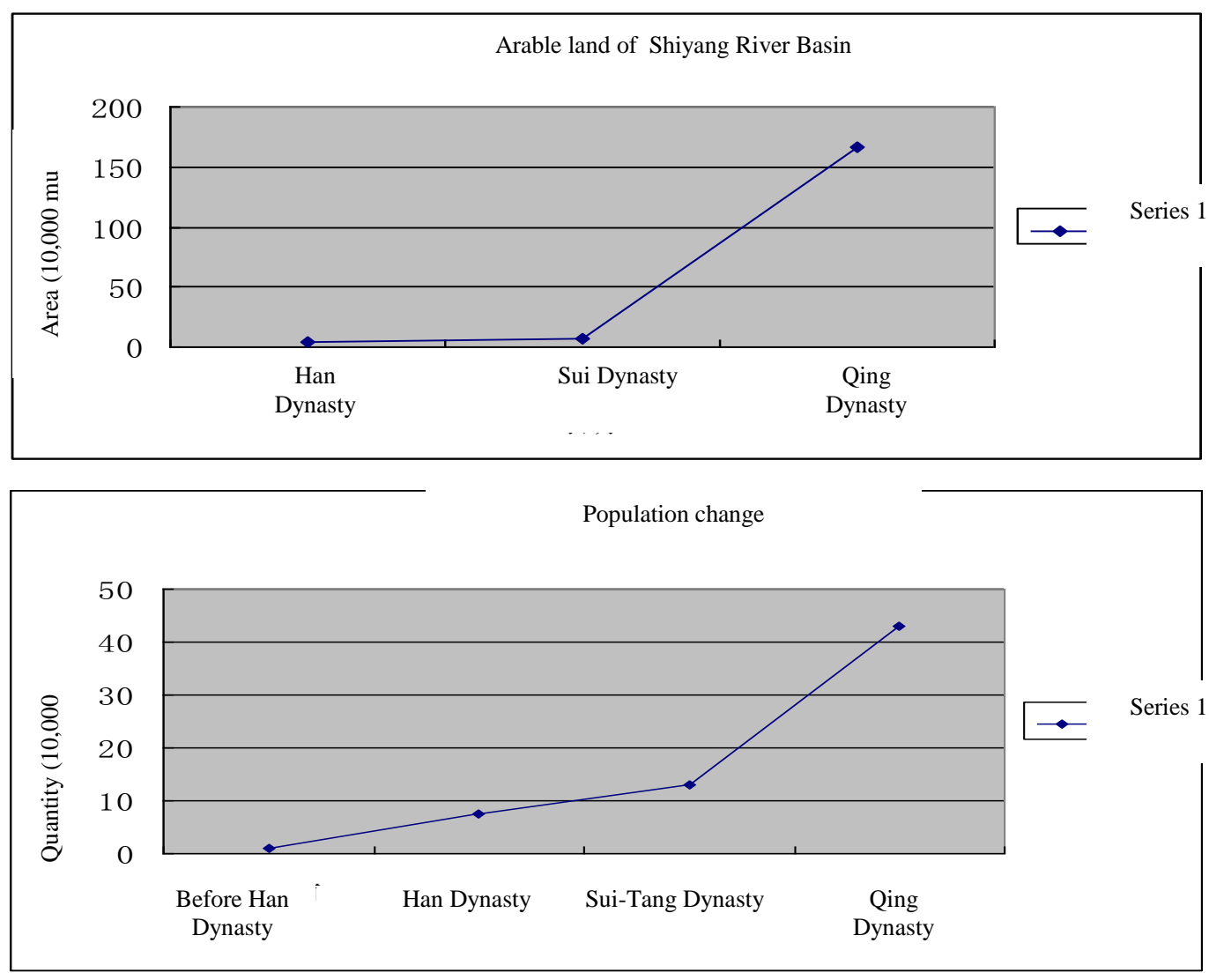

TABLE II. Human, Development AND Ecological Change IN ShiY ANg River Basin

\begin{tabular}{|c|c|c|c|c|}
\hline Period & Population & Arable land & Key point of development & Ecological change \\
\hline $\begin{array}{l}\text { Since the } \\
\text { Cretaceous }\end{array}$ & $\begin{array}{l}\text { There were human } \\
\text { activities }\end{array}$ & & & Native ecological landscape \\
\hline $\begin{array}{l}\text { Before Han } \\
\text { Dynasty }\end{array}$ & $\begin{array}{l}\text { Shajing Culture, } \\
\text { Rouzhi, the Huns }\end{array}$ & & & Native ecological landscape \\
\hline Han Dynasty & 76419 people & 4. $2 \times 104 \mathrm{hm} 2$ & $\begin{array}{l}\text { The middle and lower reaches of } \\
\text { Shiyang River }\end{array}$ & $\begin{array}{l}\text { In the area around Snajiao City and Shajing } \\
\text { Liuhudun in the southwest, covering an area } \\
\text { of about } 140 \text { square kilometers }\end{array}$ \\
\hline $\begin{array}{l}\text { Sui and Tang } \\
\text { Dynasties }\end{array}$ & $\begin{array}{l}137493 \text { people } \\
\text { (Wuwei County) }\end{array}$ & $7.3 \times 104 \mathrm{hm} 2$ & The middle reaches & $\begin{array}{l}\text { Minqin Xishawo was barren and abandoned } \\
\text { (about } 660 \text { square kilometers) }\end{array}$ \\
\hline Xixia & & & The middle and lower reaches & \\
\hline $\begin{array}{l}\text { Ming } \\
\text { Dynasty }\end{array}$ & $\begin{array}{l}3363 \text { people } \\
\text { Zhenfanwei (now } \\
\text { Minqin County) }\end{array}$ & $\begin{array}{l}\text { Newly reclaimed } \\
\text { area: } 1.3 \times 104 \mathrm{hm} 2 \text {, } \\
\text { total: } \\
800 \times 104 \mathrm{hm} 2\end{array}$ & $\begin{array}{l}\text { East of Xishaw and the dam area in } \\
\text { Minqin County in the lower reaches }\end{array}$ & $\begin{array}{l}\text { Desertification intensified in the lower } \\
\text { reaches }\end{array}$ \\
\hline Qing Dynasty & $\begin{array}{l}250000 \text { people in } \\
\text { Wuwei County, } \\
180000 \text { people in } \\
\text { Zhen Fan County }\end{array}$ & $\begin{array}{l}\text { Newly reclaimed } \\
\text { area: } 167 \times 104 \mathrm{hm} 2\end{array}$ & $\begin{array}{l}\text { The reclamation area in the lower } \\
\text { reaches broke Ming Great Wall, Liulin } \\
\text { District, Panjia Lake extented to Minqin } \\
\text { Lake }\end{array}$ & $\begin{array}{l}\text { To the end of Qing Dynasty, the desertified } \\
\text { land gradually expanded contiguously from } \\
\text { spots in the past, and Minqin oasis gradually } \\
\text { turned to an artificial oasis. }\end{array}$ \\
\hline
\end{tabular}




\section{Ecological Landscape}

It can be seen that the development and utilization of Shiyang River Basin in Ming Dynasty was mainly in the south and the vicinity of the Great Wall. The focus of the development of this area was agriculture, and the development area was obviously smaller than that of Tang Dynasty. During Ming and Qing Dynasties, Shiyang River Basin ushered in the third agricultural development. Blind agricultural development exceeded the carrying capacity of Shiyang River Basin, and the ecological environment rapidly deteriorated, the natural chain tightened, and oasis completely transformed from semiartificial oasis to an artificial one. Since then, human factors played a decisive role in the ecological changes of Shiyang River Basin, and continued to fight with the nature. They continued to suffer from the punishment of nature while achieving results.

\section{CONCLUSION}

We can see through the above analysis that the ecological changes in Shiyang River Basin was a microcosm of the ecological changes in nature, and its evolution was in line with the laws of nature. After several intense tectonic movements since the Quaternary period and the formation of Wuwei Basin, Minqin Basin, Tengger Desert and Badain Jaran Desert, the ecological environment of Shiyang River Basin was constantly changing. When the climatic environment tended to drought, the desert gradually extended to the two basins. With the human activities, the ecological balance of Shiyang River Basin was affected, and with the expansion of the scope and field of human activities, the influence became increasingly strong. Ultimately, the ecological environment of Shiyang River Basin and human economic activities depended on each other, becoming an ever evolving history of ecological and economic changes.

From the view of ecological evolution of Shiyang River Basin, the degradation of the ecosystem was due to the general trend of climate and environment to drought, as well as the interference of human's economic activity on the natural adjustment. The climate in the basin was dominated by drought in the historical period, with frequent alternation of cold and warm which made the ecological environment of Shiyang River Basin gradually deteriorate. According to this, we can divide the ecological and economic changes in Shiyang River Basin into two stages: the natural development and virtuous circle period (before Han Dynasty) and the period interfered by human activities (from Han Dynasty to Qing Dynasty). In the long years, due to the absence of human activities or small influence scope of human activities, the ecological development of the basin was good. However, with the intensification of human development and utilization, the ecology of the basin was gradually destroyed, and the selfregulating ability was weakened, and gradually became a fragile ecological environment chain strongly disturbed by human beings.

The key factors of the degradation and desertification of the ecological environment in the lower reaches of Shiyang
River were the reduction of water resources and the interference of human being to the water cycle. Agricultural development was the key to the relative reduction of water resources. With agricultural development, as well as a large amount of irrigation water in the middle reaches and a large number of waters dug, human activities changed the water circulation in Shiyang River Basin, resulting in lower surface runoff and groundwater recharge, which made farmland in the lower reaches that are abandoned and caused desertification. On the other hand, the groundwater level dropped, causing vegetation changes. Human beings' excessive wood chopping of the forest, shrubs and herbaceous vegetation caused the occurrence of desertification. Desertification began to appear in Han Dynasty, large desertification appeared in the lower reaches in Tang Dynasty, and desertification intensified during Ming and Qing Dynasties. Eventually, the natural oasis turned into artificial oasis.

Human's development activities must take into account the objective conditions and follow the laws of nature. If the development exceeds a certain limit and ignores the negative effects that may be produced, it will evolve into a natural ecological damage.

\section{REFERENCES}

[1] Gansu Institute of Cultural Relics and Archeology. Shajing Cultural Relics in Yongchang Sanjiaocheng City and Hamadun [J]. Journal of Archeology, 1990 (02).

[2] Gansu Provincial Museum. Gansu Wuwei Mojuzi Han Tomb Excavation [J]. Archaeology, 1960 (09)

[3] Li Bingcheng. Zhuyeze in the prehistoric period and its historical changes [J]. Journal of Northwest Normal University (Social Science Edition), 1992 (01)

[4] Wang Gang, Jia Bing. The history of climate change in Shiyang River Basin and its influence on hydrology and water resources [J]. Gansu Water Resources \& Hydropower Engineering, 2008 (03).

[5] Wang Gang, Jia Bing. The history of climate change in Shiyang River Basin and its influence on hydrology and water resources [J]. Gansu Water Resources \& Hydropower Engineering, 2008 (03).

[6] Wu Tingzhen, Guo Houan. Hexi Development History Research [M]. Gansu Education Press, 1996. 